\title{
Postoperative delirium in the intensive care unit predicts worse outcomes in liver transplant recipients
}

\author{
Thomas Lescot MD PhD ${ }^{1}$, Constantine J Karvellas MD FRCPC ${ }^{2}$, Prosanto Chaudhury MD FRCSC FACS ${ }^{3}$, \\ Jean Tchervenkov MD FRCSC 3 , Steven Paraskevas MD PhD ${ }^{3}$, Jeffrey Barkun MD FRCSC FACS MSc ${ }^{3}$, \\ Peter Metrakos MD FRCSC FACS ${ }^{3}$, Peter Goldberg MD FRCPC ${ }^{1}$, Sheldon Magder MD FRCPC ${ }^{1}$
}

T Lescot, CJ Karvellas, P Chaudhury, et al. Postoperative delirium in the intensive care unit predicts worse outcomes in liver transplant recipients. Can J Gastroenterol 2013;27(4):207212.

BACKGROUND: Delirium is common in intensive care unit patients and is associated with worse outcome.

OBJECTIVE: To identify early risk factors for delirium in patients admitted to the intensive care unit following orthotopic liver transplantation (OLT).

METHODS: An observational study of patients admitted to the intensive care unit from January 2000 to May 2010 for elective or semielective OLT was conducted. The primary end point was delirium in the intensive care unit. Pre- and post-transplantation and intraoperative factors potentially associated with this outcome were examined. RESULTS: Of the 281 patients included in the study, 28 (10.03\%) developed delirium in the intensive care unit at a median of two days (interquartile range one to seven days) after OLT. According to multivariate analysis, independent risk factors for delirium were intraoperative transfusion of packed red blood cells (OR 1.15 [95\% CI 1.01 to 1.18]), renal replacement therapy during the pretransplantation period (OR 13.12 [95\% CI 2.82 to 72.12]) and Acute Physiologic and Health Evaluation (APACHE) II score (OR per unit increase 1.10 [95\% CI 1.03 to 1.29]). Using Cox proportional hazards models adjusted for baseline covariates, delirium was associated with an almost twofold risk of remaining in hospital, a fourfold increased risk of dying in hospital and an almost threefold increased rate of death by one year. CONCLUSION: Intraoperative transfusion of packed red blood cells, pretransplantation renal replacement therapy and APACHE II score are predictors for the development of delirium in intensive care unit patients post-OLT and are associated with increased hospital lengths of stay and mortality.

Key Words: Delirium; Intensive care unit; Liver transplantation; Neurological complication

\section{Le délire postopératoire à l'unité de soins intensifs prédicteur d'issues plus négatives chez les greffés du foie}

HISTORIQUE : Le délire est courant à l'unité de soins intensifs et est
prédicteur d'issues plus négatives. OBJECTIF : Déterminer les facteurs de risque précoces de délire chez les parents admis à l'unité de soins intensifs après une transplantation hépatique orthotopique (THO).

MÉTHODOLOGIE : Les chercheurs ont mené une étude d'observation de patients admis à l'unité de soins intensifs entre janvier 2000 et mai 2010 en vue d'une THO non urgente ou semi-urgente. Le délire à l'unité de soins intensifs en était le paramètre primaire. Ils ont examiné les facteurs post-transplantation et intraopératoires susceptibles de s'associer à cette issue.

RÉSULTATS : Sur les 281 patients qui ont participé à l'étude, 28 (10,03\%) ont présenté du délire à l'unité de soins intensifs à une médiane de deux jours (plage interquartile de un à sept jours) après la THO. Selon l'analyse multivariée, les facteurs de risque indépendants de délire étaient une transfusion intraopératoire de culots globulaires (RRR 1,15 [95\% IC 1,01 à 1,18]), une thérapie de substitution rénale avant la transplantation (RRR 13,12 [95 \% IC 2,82 à 72,12]) et un score d'évaluation APACHE II de physiologie aiguë et de maladie chronique (augmentation du RRR par unité de 1,10 [95 \% IC 1,03 à 1,29]). Au moyen des modèles des risques proportionnels de Cox rajustés pour tenir compte des covariables de départ, le délire s'associait à presque deux fois le risque de demeurer hospitalisé et à quatre fois le risque de mourir à l'hôpital ainsi qu'à près de trois fois le nombre de décès au bout d'un an.

CONCLUSION : La transfusion intraopératoire de culots globulaires, la thérapie de substitution rénale avant la transplantation et un score APACHE II sont des prédicteurs de délire à l'unité de soins intensifs après une $\mathrm{THO}$ et s'associent à une hospitalisation plus longue ainsi qu'à un plus fort taux de mortalité.

\footnotetext{
$\mathrm{D}_{\mathrm{c}}^{\mathrm{d}}$ lirium represents an acute confusional state or mental status change associated with inattention and disorganized thinking or an altered level of consciousness (1). Delirium occurs frequently in patients hospitalized in the intensive care unit (ICU), and postoperatively in older adults, cardiac and orthopedic surgery patients $(2,3)$. In the ICU, patients who develop delirium experience increased lengths of stay, higher short- and long-term mortality rates, and increased long-term cognitive impairment, which result in higher health care costs (4-7). Development of delirium is related to both predisposing and precipitating factors (3). Accordingly, liver transplant recipients are at a particularly high risk for delirium, not only because they are hospitalized in the ICU - a recognized precipitating factor - but also because liver disease affects brain metabolism (8) and constitutes a predisposing factor for delirium development (9).
}

Neurological complications can occur during the first few months post-orthotopic liver transplantation (OLT), and acute brain dysfunction, including encephalopathy, delirium or confusion, are the most common causes, with a prevalence of $12 \%$ to $32 \%$ in transplant recipients (10). However, little data regarding early risk factors and consequences of postoperative ICU delirium in liver transplant recipients are available. Identification of early risk factors for delirium could help detect high-risk patients and enable preventive, supportive and treatment strategies and pharmacological therapies and, thereby, improve outcome (11-14).

Accordingly, our objective in the present study was to identify risk factors on admission to the ICU for delirium in cirrhotic patients admitted to the ICU following OLT and to determine the effect of delirium on patient outcomes post-OLT.

${ }^{1}$ Critical Care Division, Royal Victoria Hospital, McGill University Health Centre, Montreal, Quebec; ${ }^{2}$ Division of Gastroenterology (Liver Unit) and Critical Care Medicine, University of Alberta, Edmonton, Alberta; ${ }^{3}$ Department of Surgery and Multi-Organ Transplant Program, Victoria Hospital, McGill University Health Centre, Montreal, Quebec

Correspondence: Dr Thomas Lescot, Réanimation chirurgicale, Département d'Anesthésie Réanimation, Hôpital Saint Antoine, 184 rue du Faubourg Saint Antoine, 75012 Paris, France. Telephone 33-1-49-28-2362, fax 1-33-49-28-2826, e-mail thomas.lescot@sat.aphp.fr

Received for publication April 20, 2012. Accepted January 30, 2013 


\section{METHODS}

Patients

The present observational study was conducted in compliance with published Strengthening the Reporting of Observational Studies in Epidemiology (STROBE) guidelines (15), with slight adjustments detailed below. The access to health information was approved by the Director of Professional Services, who waived the need for individual consent according to Quebec law (Loi sur les services de santé et les services sociaux). Consecutive adult patients admitted to the ICU after cadaveric OLT from January 2000 to May 2010 were studied. Exclusion criteria were hospitalization in the ICU at the time of the transplantation, multiorgan transplantation, retransplantation and early death defined as death occurring within the first four days after OLT.

\section{Perioperative procedure}

OLT was performed as previously described $(16,17)$. Briefly, transplant recipients were admitted to the ICU after the transplantation procedure, sedated and mechanically ventilated in the immediate postoperative period. Extubation was performed after ICU admission once hemodynamic and respiratory function were stabilized. Induction of immunosupression included antithymocyte globulin $(6 \mathrm{mg} / \mathrm{kg} /$ day administered in divided doses starting on postoperative day 1 or 2 ), tacrolimus (target levels of $8 \mathrm{ng} / \mathrm{mL}$ to $10 \mathrm{ng} / \mathrm{mL}$ ) or cyclosporine $\left(\mathrm{C}_{2}\right.$ target levels of $600 \mathrm{ng} / \mathrm{mL}$ to $800 \mathrm{ng} / \mathrm{mL}$ ), mofetil myclophenolate or azathioprine and steroids. Maintenance immunosupression included tacrolimus (target levels of $8 \mathrm{ng} / \mathrm{mL}$ to $12 \mathrm{ng} / \mathrm{mL}$ ) or cyclosporine $\left(\mathrm{C}_{2}\right.$ target levels of $300 \mathrm{ng} / \mathrm{mL}$ to $600 \mathrm{ng} / \mathrm{mL}$ ), mofetil myclophenolate, or azathioprine and prednisone.

\section{Data collection}

Factors from the pretransplant, post-transplantation and the intraoperative periods describing the population and factors potentially associated with outcomes were prospectively collected and entered into a dedicated database. Age at the time of OLT, sex and etiology of liver disease were recorded. Transplant recipients were defined as elective if patients came from home or semielective if they came from the ward. Model for End-stage Liver Disease (MELD) scores were calculated at the time of OLT. The MELD score, calculated from total bilirubin, creatinine and international normalized ratio (INR) values, ranges from 6 to 40 with higher score indicating more severe liver disease (18). Child-Pugh score, a reflection of liver disease severity before transplantation, was calculated based on INR, albumin and bilirubin levels, and the presence of ascites and hepatic encephalopathy determined at the time of transplantation. Pretransplant hepatic encephalopathy grade $\geq 2$, the need for renal replacement therapy (RRT) before transplantation, as well as intraoperative features, including duration of surgery and packed red blood cell (PRBC) transfusion requirements, were recorded. The Acute Physiologic and Chronic Health Evaluation (APACHE) II score was used to assess illness severity at ICU admission. APACHE II is based on 12 clinical and biological measurement at admission (from 0 to 71 ), with a high score indicating high predicted in-hospital mortality (19). The serum sodium shift refers to the difference between mean serum sodium level $48 \mathrm{~h}$ after liver transplant and mean serum sodium level $48 \mathrm{~h}$ before liver transplant. Immunosuppressant therapy provided while in ICU after liver transplantation was reported.

\section{Ends points}

For the present retrospective study, validated methods of delirium assessment were not available. Neurological status was assessed daily by the attending nurse and delirium/confusion status was confirmed by the senior intensivist. Patients were diagnosed with delirium if they presented with an acute confusional state or mental status changes with inattention, disorganized thinking or altered level of consciousness (1) that were not considered to be hepatic encephalopathy by the physician in charge. Hepatic encephalopathy was considered in patients presenting with mental status changes and concomitant signs of liver dysfunction/failure. Patients underwent psychiatric assessment when deemed necessary by the senior ICU physician. Charts of patients who presented with delirium were reviewed. The primary outcome was in-hospital mortality. Secondary end points were oneyear mortality and in-hospital length of stay.

\section{Statistical analysis}

Data are expressed as median with the interquartile range (IQR) for normal and non-normal quantitative variables, and numbers with percentages for qualitative variables. The Shapiro-Wilk test was used to assess normality. The unpaired Student's $t$ test was used for data that were normally distributed; the Mann-Whitney-Wilcoxon test was used to compare non-normally distributed data; and Fisher's exact method was used to compare proportions. Stepwise logistic regression was performed to identify independent risk factors for delirium. A semiparsimonious approach was used and previously described clinical relevant factors with $\mathrm{P}<0.1$ in the univariate analysis were included in the final model. OR with $95 \%$ CIs were reported for significant results. Discrimination of the final models was assessed using the area under the curve and calibration using the goodness-of-fit statistic. KaplanMeier curves were used for graphical representation of hospital length of stay and one-year mortality, the log rank test was used to assess differences between patients with delirium and patients without. Cox proportional hazards models was constructed to obtain HR with 95\% CIs measuring the association between delirium in ICU and outcome including hospital length of stay, in-hospital mortality and one-year mortality. Baseline covariates were chosen a priori based on their previously described clinical relevance and included APACHE II score, MELD score and age. Because MELD and APACHE II scores were collinear, two different models were constructed independently. To assess one-year mortality, patients were censored if they were alive at one year. For in-hospital mortality analysis, patients were censored if they were alive at hospital discharge. For in-hospital length of stay analysis, patients were censored at the time of hospital death. Collinearity between variables was assessed by examining the variance inflation factor, with variance inflation factor $\geq 10$ indicating collinearity. $\mathrm{P}$ values were two-tailed and $\mathrm{P}<0.05$ was considered to be statistically significant. Statistical analysis was performed using JMP version 8.0 (SAS Institute, USA).

\section{Patients}

\section{RESULTS}

During the 10-year study period, 421 OLT were performed in 369 patients (35 patients were transplanted two times, seven patients were transplanted three times and one patient four times). Of these 369 patients, 88 were excluded for the following reasons: death before day $5(n=14)$, combined transplantation ( $\mathrm{n}=14$ [kidney-liver in 12 patients and heart-liver in two patients]), lost to follow-up ( $n=14)$, acute liver failure $(n=11)$ and hospitalized in the ICU at the time of the transplantation $(n=35)$. This left 281 patients who were admitted to the ICU after OLT. The median ICU length of stay was five days (IQR three to five days). Of the 281 patients, 28 (10.03\%) developed delirium in two days (IQR one to seven days) after OLT.

\section{Risk factors for delirium following OLT}

Table 1 summarizes the pre-OLT and ICU admission features in patients diagnosed with delirium and patients without. Neither age nor etiology of cirrhosis was significantly associated with delirium. The risk of developing delirium was greater in patients with pretransplantation encephalopathy $(\mathrm{P}=0.02)$ and in patients who underwent RRT during the pretransplantation period $(\mathrm{P}<0.01)$. Delirium was not significantly associated with age, MELD or Child-Pugh score. The median number of intraoperative transfused PRBC units in patients with delirium was more than double that of in patients without delirium $(\mathrm{P}=0.001)$. Patients who developed delirium post-OLT had significantly higher APACHE II scores on ICU admission (24 versus 21; $\mathrm{P}=0.02$ ). Importantly, immunosuppressant therapy did not differ 
TABLE 1

Comparison of admission, etiology of liver transplant and perioperative characteristics for patient with/without intensive care unit (ICU) delirium following liver transplant

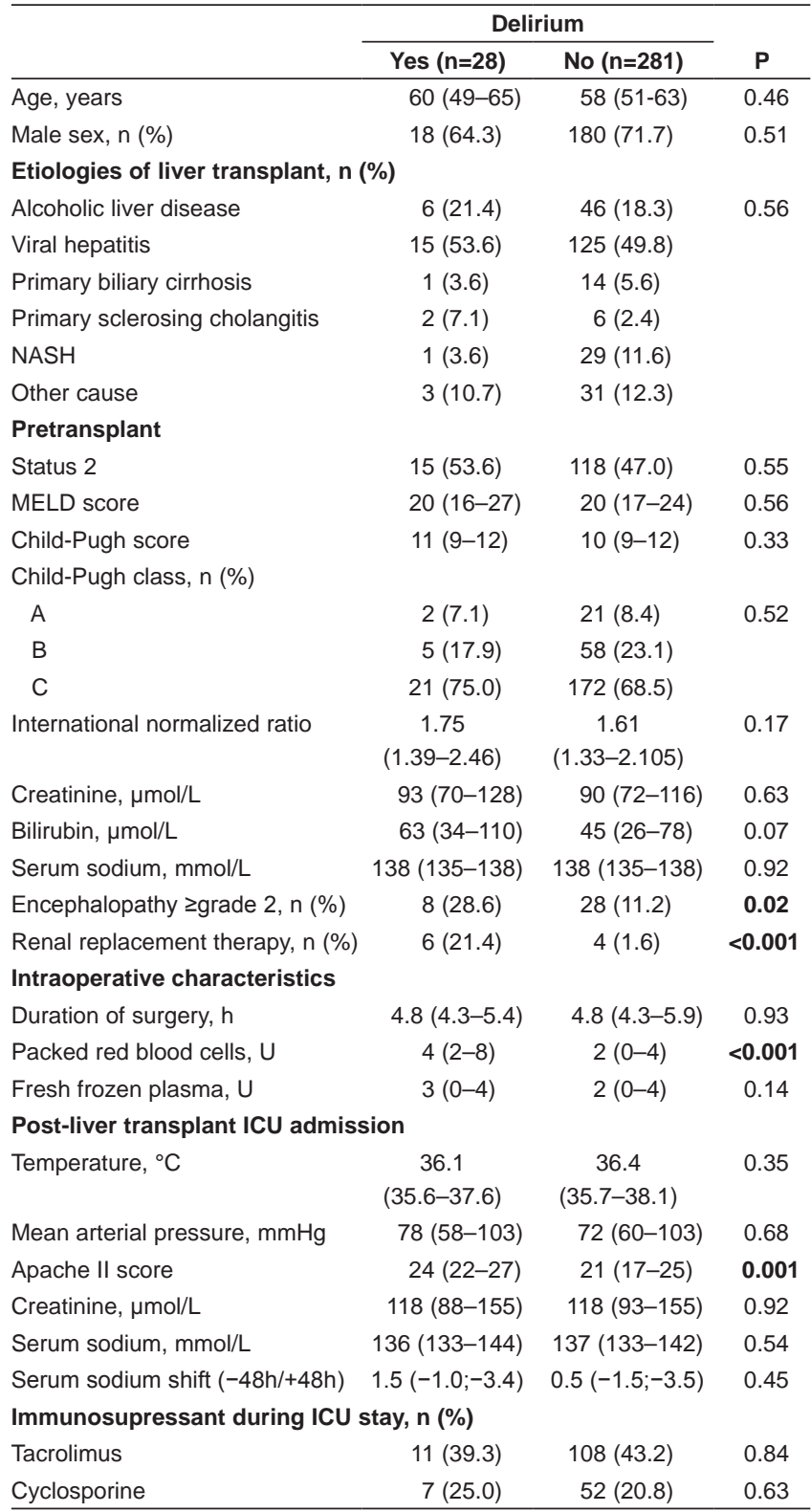

Data presented as mean (interquartile range) unless indicated otherwise. Bolded values indicate statistical significance. APACHE Acute Physiologic and Chronic Health Evaluation; INR International normalized ratio; IQR Interquartile range; MELD Model for End-stage Liver Disease; NASH Nonalcoholic steatohepatitis

significantly between the two groups. To avoid overfitting, only three factors that were associated with delirium were entered into the final model using a semiparsimonious approach: number of transfused units of PRBC; pre-OLT need for dialysis; and high APACHE II score (Table 2). The final model demonstrated good discrimination (area under the curve $=0.77$ ) and calibration (testing showed no significant lack of fit: goodness-of-fit test $\mathrm{P}=0.9$ ).

Short- and long-term consequences of delirium following OLT Primary and secondary outcomes are shown in Table 3. Patients with ICU delirium experienced significantly more frequent episodes of sepsis/ septic shock in the ICU, spent significantly more time on mechanical
TABLE 2

Logistic regression multivariate analysis of factors present at intensive care admission and associated with delirium during intensive care unit stay

\begin{tabular}{lcl}
\hline & OR (95\% Cl) & \multicolumn{1}{c}{$\mathbf{P}$} \\
\hline PRBC (per PRBC unit increase) & $1.15(1.01-1.18)$ & 0.01 \\
RRT preliver transplant & $13.12(2.82-72.12)$ & 0.001 \\
APACHE Il score (per unit increase) & $1.10(1.03-1.29)$ & 0.02 \\
\hline
\end{tabular}

C-statistic $=0.77$. APACHE Acute Physiologic and Chronic Health Evaluation; PRBC Packed red blood cells; RRT Renal replacement therapy

TABLE 3

Postoperative outcome for patients with/without delirium following orthotopic liver transplant (OLT)

\begin{tabular}{|c|c|c|c|}
\hline & \multicolumn{2}{|c|}{ Delirium } & \multirow[b]{2}{*}{$\mathbf{P}$} \\
\hline & $\begin{array}{c}\text { Yes } \\
(n=28)\end{array}$ & $\begin{array}{c}\text { No } \\
(n=281)\end{array}$ & \\
\hline \multicolumn{4}{|l|}{ Hospital outcomes } \\
\hline Sepsis during ICU stay & $5(17.8)$ & $3(1.2)$ & $<0.001$ \\
\hline $\begin{array}{l}\text { Mechanical ventilation after OLT, } \\
\text { days, mean (IQR) }\end{array}$ & $2(1-5)$ & $1(1-2)$ & $<0.001$ \\
\hline RRT in ICU after OLT & $5(18.5)$ & $23(9.2)$ & 0.17 \\
\hline $\begin{array}{l}\text { ICU length of stay after OLT, } \\
\text { days, mean (IQR) }\end{array}$ & $9(7-17)$ & $4(3-7)$ & $<0.001$ \\
\hline $\begin{array}{l}\text { Hospital length of stay after OLT, } \\
\text { days, mean (IQR) }\end{array}$ & $37(25-84)$ & $20(14-32)$ & $<0.001$ \\
\hline Retransplant & $4(14.3)$ & $25(10.0)$ & 0.61 \\
\hline Graft failure during ICU stay & $3(10.7)$ & $8(3.2)$ & 0.09 \\
\hline \multicolumn{4}{|l|}{ Mortality } \\
\hline ICU & $3(10.7)$ & $5(2.0)$ & 0.04 \\
\hline In-hospital & $7(25)$ & $15(6.0)$ & 0.003 \\
\hline One-year & $9(32.1)$ & 30 (11.9) & 0.007 \\
\hline
\end{tabular}

Data presented as $n$ (\%) unless otherwise indicated. ICU Intensive care unit; IQR Interquartile range; RRT Renal replacement therapy

ventilation and had longer median ICU stays. Patients who developed delirium in the ICU had a significantly longer median hospital length of stay compared with controls. A Kaplan-Meier plot for the probability of remaining in hospital in patients with or without delirium is presented in Figure 1. Cox proportional hazards models were used to adjust for baseline covariates including age, MELD and APACHE II scores. Because MELD and APACHE II scores were collinear, two separate models were constructed. When adjusting on MELD score and age, the adjusted risk for transplant patients with delirium remaining in hospital was more than twice as high as controls (Table 4). A similar result was found after adjustment on APACHE II score and age.

Of the 280 patients included in the study, 22 (7.6\%) died in hospital and 39 died at one year (13.9\%). In-hospital and one-year mortality rates were significantly increased in transplant patients who developed delirium during their ICU stay (Table 3). Kaplan-Meier curve estimating one-year survival in patients with and without delirium is shown in Figure 1B. After adjustment for baseline covariates, delirium was associated with an almost fourfold increased risk of dying in hospital and an almost threefold increased rate of death by one year in both models (Table 4).

\section{DISCUSSION}

To the best of our knowledge, the present study was the first cohort analysis investigating the incidence and risk factors for delirium in OLT recipients in the ICU. In our single-centre study, delirium occurred in almost $10 \%$ of elective and semielective liver transplant recipients and was associated with increased ICU length of stay, inhospital mortality and one-year mortality. Multivariate analysis 


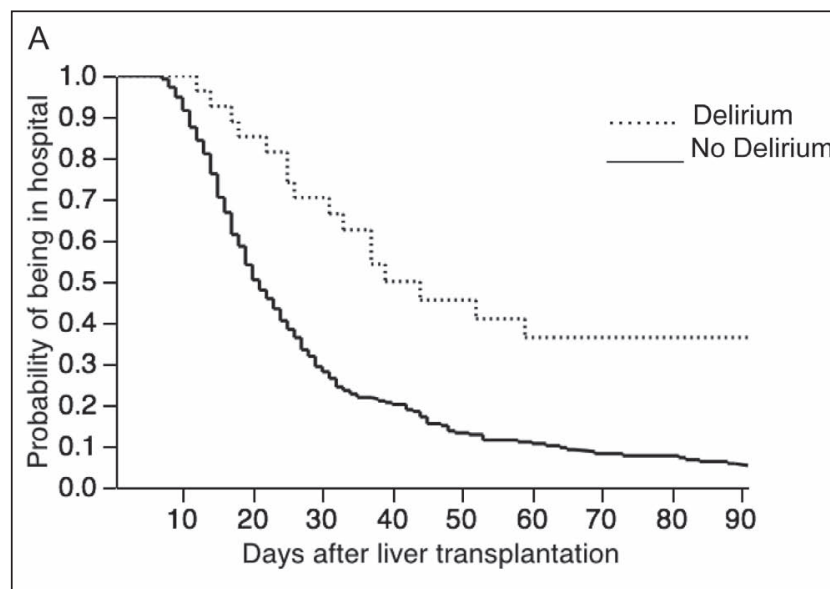

B

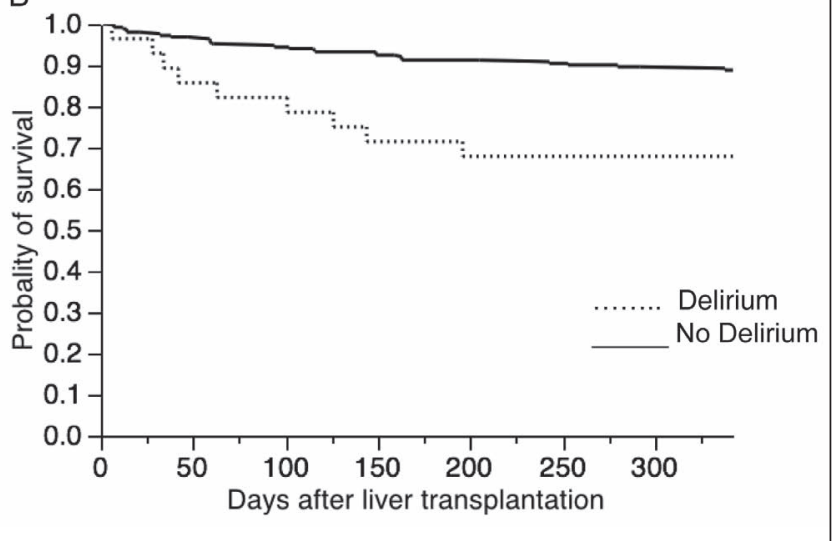

Figure 1) Kaplan-Meier plot describing the length of stay. A Log-rank test $(P<0.001)$ and one-year survival experience. B Log-rank test $(P=0.02)$ of liver transplant patients with and without delirium in the intensive care unit

identified intraoperative PRBC transfusions, APACHE II score and pretransplantation need for dialysis as admission risk factors of ICU delirium.

In previous studies, neurological complications were reported in almost $30 \%$ of patients, and occurred preferentially during the first month after OLT (20-22). These included both preventable and treatable complications such as delirium, seizure, calcineurin inhibitor neurotoxicity and central pontine myelinolysis. Importantly, these studies did not differentiate complications occurring in the ICU from those developing on the hospital ward. In our analysis, which was restricted to delirium in the ICU, delirium prevalence was 10\%, which is similar to the value of $11 \%$ of patients with diffuse encephalopathy after OLT reported by Lewis and Howdle (23) and not far from the $16 \%$ of patients with delirium in the postoperative period after OLT reported by Burkhalter et al (24). Although similar prevalences have been reported in other solid organ transplant recipients, such as heart transplant patients (25), higher prevalences have also been observed when considering the postoperative period in surgical patients (2) or medicosurgical ICU populations in which the incidence of delirium has been reported to be as high as $80 \%(26,27)$. These differences in reporting delirium incidence across studies may be ascribed, in part, to the methods used for measuring delirium. Due to the retrospective nature of our study and the lack of use of a validated delirium score, we likely underestimated the true incidence of delirium in our population $(28,29)$. This, however, should be tempered by the fact that the performance of scoring methods between the research setting and clinical practice has been shown to be different, with low sensitivity when validated scoring methods were routinely performed (26).
TABLE 4

Adjusted HR for delirium in intensive care unit (ICU) and clinical outcome defined by hospital length of stay, in-hospital mortality and one-year mortality

\begin{tabular}{llc}
\hline Delirium in ICU & Adjusted HR (95\% CI) & P \\
\hline Model A* & & \\
Hospital length of stay & $2.37(1.54-3.85)$ & $<0.001$ \\
In-hospital mortality & $4.30(1.62-10.34)$ & 0.005 \\
One-year mortality & $2.90(1.29-5.91)$ & 0.001 \\
Model B $^{\dagger}$ & & \\
Hospital length of stay & $2.18(1.40-3.57)$ & 0.0003 \\
In-hospital mortality & $4.59(1.66-11.69]$ & 0.005 \\
One-year mortality & $3.35(1.44-7.09)$ & 0.006 \\
\hline
\end{tabular}

*HR adjusted on baseline covariate Model for End-stage Liver Disease score and age; ${ }^{\dagger} \mathrm{HR}$ adjusted on baseline covariate including Acute Physiologic and Chronic Health Evaluation II score and age

Risk factors for delirium following OLT

We identified early risk factors for delirium in the ICU: intraoperative transfusion of PRBC, pretransplantation RRT and high APACHE II score. All three factors can be easily assessed at admission, which may help to stratify patients presenting post-OLT. Only a few clinical studies are available for comparison. Dhar et al (20) found that only pre-OLT encephalopathy was associated with delirium occurring within the first month after the transplant procedure. In our population, the etiology of liver disease was not associated with delirium, which is in contrast to a previous report that showed a significantly increased rate of postoperative acute confusional state in patients receiving liver transplants for alcoholic cirrhosis (30). We did not observe acute brain dysfunction induced by drug toxicity from agents such as calcineurin inhibitors. This complication most commonly occurs seven to 10 days after OLT (31), which is more than the fiveday median ICU length of stay observed here and corresponding to the study period. Although our perioperative anesthesia protocol was not detailed, Marcantonio et al (32) found that anesthesia or intraoperative complications were not associated with postoperative delirium. In a second analysis, the same authors found that only hematocrit $<30 \%$ was associated with an increased risk of delirium, suggesting an association between blood loss and PRBC transfusion (33). In the current study, PRBC transfusion was associated with an increased risk of postoperative delirium in the ICU. An association between PRBC transfusion and delirium has been shown previously in cardiac $(34,35)$ and vascular surgery patients (36). Difficult surgery or transient hypoperfusion and consequent liver injury have been proposed to explain this association. We also found a strong association between pretransplant RRT and delirium. RRT has been previously associated with ICU delirium (37). Such association between acute renal failure and postoperative delirium has also been found in elderly patients after cardiac surgery (38). Serum sodium and other electrolyte imbalances due to dialysis may constitute one possible explanation. Nevertheless, in our population, sodium shift did not significantly differ between patients who presented with delirium and patients who did not. The association between APACHE II score and delirium has been previously reported and it has been suggested that patients presenting with more severe illness when admitted in the ICU were more sensitive to developing delirium $(39,40)$.

Although the exact causes of postoperative and ICU delirium are unknown, the role of predisposing and precipitating factors have been well described: major surgery, including abdominal and cardiac surgery, and ICU admission have been identified as precipitating factors leading to the development of delirium $(3,38)$. Because liver disease may affect the brain, it may represent a predisposing situation that is precipitated by surgery and ICU admission. Neuroinflammation has been proposed to be associated with delirium and various putative theories 
have been discussed in which microglia activation appears to play a crucial role $(41,42)$. Furthermore, altered astrocyte morphology (43), brain metabolism (8), brain perfusion (44) and blood-brain barrier permeability associated with hepatic encephalopathy put the liver transplant recipient at a particularly high risk for subsequent development of delirium in the ICU.

\section{Consequences of delirium following OLT}

Patients who presented with delirium in the ICU post-OLT experienced increased hospital length of stay, and increased in-hospital and one-year mortality consistent with previous studies indicating worse outcome both in medical ICU and postoperative patients who developed delirium $(6,40)$. Modifiable factors, such as environment, have been shown to be associated with ICU delirium. Patients with isolation, lack of visible daylight, absence of visitors and physical restraints are more likely to develop ICU delirium and implementation or re-enforcement of nonpharmacological measures have been proven to decrease ICU delirium. Such measures include prevention of sleep deprivation, multiple psychoactive medications, support of mobilization, reorientation, vision and hearing aids, and targeted management of pain and sedation $(11,45,46)$. One unresolved question is whether delirium that appears as a reversible condition may affect long-term outcome as observed in our study and in others $(6,7)$.

\section{Limitations}

There are several limitations to our study. First, our study was retrospective in nature; therefore, causality cannot be established. Delirium could be a marker of disease, the results of damage from previous exposures or related to comorbidities. Second, the relatively small number of patients and the low number of cases limits the value of the

\section{REFERENCES}

1. Diagnostic and Statistical Manual of Mental Disorders, 4th edn. Washington, DC: American Psychiatric Association, 1994.

2. Dasgupta M, Dumbrell AC. Preoperative risk assessment for delirium after noncardiac surgery: A systematic review. J Am Geriatr Soc 2006;54:1578-89.

3. Steiner LA. Postoperative delirium. Part 1: Pathophysiology and risk factors. Eur J Anaesthesiol 2011;28:628-36.

4. Milbrandt EB, Deppen S, Harrison PL, et al. Costs associated with delirium in mechanically ventilated patients. Crit Care Med 2004;32:955-62.

5. Lin SM, Liu CY, Wang CH, et al. The impact of delirium on the survival of mechanically ventilated patients. Crit Care Med 2004:32:2254-9.

6. Ely EW, Shintani A, Truman B, et al. Delirium as a predictor of mortality in mechanically ventilated patients in the intensive care unit. JAMA 2004;291:1753-62.

7. Girard TD, Jackson JC, Pandharipande PP, et al. Delirium as a predictor of long-term cognitive impairment in survivors of critical illness. Crit Care Med 2010;38:1513-20.

8. Laubenberger J, Haussinger D, Bayer S, Gufler H, Hennig J, Langer M. Proton magnetic resonance spectroscopy of the brain in symptomatic and asymptomatic patients with liver cirrhosis. Gastroenterology 1997;112:1610-6.

9. Trzepacz PT, DiMartini A. Survival of 247 liver transplant candidates. Relationship to pretransplant psychiatric variables and presence of delirium. Gen Hosp Psychiatry 1992;14:380-6.

10. Bronster DJ, Emre S, Boccagni P, Sheiner PA, Schwartz ME, Miller CM. Central nervous system complications in liver transplant recipients - incidence, timing, and long-term follow-up. Clin Transplant 2000;14:1-7.

11. Young J, Murthy L, Westby M, Akunne A, O’Mahony R. Diagnosis, prevention, and management of delirium: Summary of NICE guidance. BMJ 2010;341:c3704.

12. Reade MC, O'Sullivan K, Bates S, Goldsmith D, Ainslie WR, Bellomo R. Dexmedetomidine vs. haloperidol in delirious, agitated, intubated patients: A randomised open-label trial. Crit Care 2009;13:R75.

13. Milbrandt EB, Kersten A, Kong L, et al. Haloperidol use is associated with lower hospital mortality in mechanically ventilated patients. Crit Care Med 2005;33:226-9. multivariate analysis (ie, overfitting) to identify event predictors such as preoperative blood transfusion, duration of delirium, serum levels of tacrolimus or cyclosporine. Further prospective studies that include a larger patient population and formal assessment of delirium are required to confirm our findings. Third, our data from a single centre may not apply to all other centres and the selected population ('elective' cirrhotic liver transplant recipients) does not allow generalization to all OLT. Finally, the absence of details regarding sedation protocol and medication used in the ICU constitutes a potential weakness because it has been shown that sedative administration may be independently linked to delirium.

\section{CONCLUSION}

Delirium complicating ICU stay postelective and semielective OLT is associated with increased hospital length of stay, and in-hospital and one-year mortality. Intraoperative transfusion of PRBC, pretransplantation RRT and APACHE II score at ICU admission have been identified as predictors for delirium development in the ICU. Further prospective studies with a larger patient population and formal assessment of delirium are required to confirm our findings.

ACKNOWLEDGEMENTS: Thomas Lescot received research fellowship grants from La Fondation des Gueules Cassées (Paris, France) and the Assistance Publique-Hôpitaux de Paris (AP-HP; Paris, France). This work was performed at Royal Victoria Hospital - McGill University Health Centre, Montréal, Quebec, and should be attributed to this institution.

DISCLOSURES: The authors have no finacial disclosures, competing interests or conflicts of interest to declare.

14. Heymann A, Radtke F, Schiemann A, et al. Delayed treatment of delirium increases mortality rate in intensive care unit patients. J Int Med Res 2010;38:1584-95.

15. Vandenbroucke JP, von Elm E, Altman DG, et al. Strengthening the Reporting of Observational Studies in Epidemiology (STROBE): Explanation and elaboration. PLoS Med 2007;4:e297.

16. Vrochides D, Hassanain M, Barkun J, et al. Association of preoperative parameters with postoperative mortality and long-term survival after liver transplantation. Can J Surg 2011;54:101-6.

17. Vrochides D, Hassanain M, Metrakos P, et al. Re-vascularization may not increase graft survival after hepatic artery thrombosis in liver transplant recipients. Hippokratia 2010;14:115-8.

18. Wiesner R, Edwards E, Freeman R, et al. Model for end-stage liver disease (MELD) and allocation of donor livers. Gastroenterology 2003;124:91-6.

19. Knaus WA, Draper EA, Wagner DP, Zimmerman JE. APACHE II: A severity of disease classification system. Crit Care Med 1985;13:818-29.

20. Dhar R, Young GB, Marotta P. Perioperative neurological complications after liver transplantation are best predicted by pre-transplant hepatic encephalopathy. Neurocrit Care 2008;8:253-8.

21. Guarino M, Stracciari A, Pazzaglia P, et al. Neurological complications of liver transplantation. J Neurol 1996;243:137-42.

22. Pujol A, Graus F, Rimola A, et al. Predictive factors of in-hospital CNS complications following liver transplantation. Neurology 1994:44:1226-30.

23. Lewis MB, Howdle PD. Neurologic complications of liver transplantation in adults. Neurology 2003;61:1174-8.

24. Burkhalter EL, Starzl TE, Van Thiel DH. Severe neurological complications following orthotopic liver transplantation in patients receiving FK 506 and prednisone. J Hepatol 1994;21:572-7.

25. van de Beek D, Kremers W, Daly RC, et al. Effect of neurologic complications on outcome after heart transplant. Arch Neurol 2008;65:226-31.

26. van Eijk MM, van den Boogaard M, van Marum RJ, et al. Routine use of the confusion assessment method for the intensive care unit: A multicenter study. Am J Respir Crit Care Med 2011;184:340-4.

27. Pandharipande PP, Pun BT, Herr DL, et al. Effect of sedation with dexmedetomidine vs lorazepam on acute brain dysfunction in mechanically ventilated patients: The MENDS randomized controlled trial. JAMA 2007;298:2644-53. 
28. Spronk PE, Riekerk B, Hofhuis J, Rommes JH. Occurrence of delirium is severely underestimated in the ICU during daily care. Intensive Care Med 2009;35:1276-80.

29. Devlin JW, Fong JJ, Schumaker G, O'Connor H, Ruthazer R, Garpestad E. Use of a validated delirium assessment tool improves the ability of physicians to identify delirium in medical intensive care unit patients. Crit Care Med 2007;35:2721-4.

30. Buis CI, Wiesner RH, Krom RA, Kremers WK, Wijdicks EF. Acute confusional state following liver transplantation for alcoholic liver disease. Neurology 2002;59:601-5.

31. Balderramo D, Prieto J, Cardenas A, Navasa M. Hepatic encephalopathy and post-transplant hyponatremia predict early calcineurin inhibitor-induced neurotoxicity after liver transplantation. Transpl Int 2011;24:812-9.

32. Marcantonio ER, Goldman L, Mangione CM, et al. A clinical prediction rule for delirium after elective noncardiac surgery. JAMA 1994;271:134-9.

33. Marcantonio ER, Goldman L, Orav EJ, Cook EF, Lee TH. The association of intraoperative factors with the development of postoperative delirium. Am J Med 1998;105:380-4.

34. Bucerius J, Gummert JF, Borger MA, et al. Predictors of delirium after cardiac surgery delirium: Effect of beating-heart (off-pump) surgery. J Thorac Cardiovasc Surg 2004;127:57-64.

35. Norkiene I, Ringaitiene D, Misiuriene I, et al. Incidence and precipitating factors of delirium after coronary artery bypass grafting. Scand Cardiovasc J 2007;41:180-5.

36. Bohner H, Hummel TC, Habel U, et al. Predicting delirium after vascular surgery: A model based on pre- and intraoperative data. Ann Surg 2003;238:149-56.

37. Watts G, Roberts BL, Parsons R. Delirium in the intensive care unit: Searching for causes and sources. Crit Care Resusc 2007;9:26-9.
38. Bakker RC, Osse RJ, Tulen JH, Kappetein AP, Bogers AJ. Preoperative and operative predictors of delirium after cardiac surgery in elderly patients. Eur J Cardiothorac Surg 2012;41:544-9.

39. Pandharipande P, Shintani A, Peterson J, et al. Lorazepam is an independent risk factor for transitioning to delirium in intensive care unit patients. Anesthesiology 2006;104:21-6.

40. Ouimet S, Kavanagh BP, Gottfried SB, Skrobik Y. Incidence, risk factors and consequences of ICU delirium. Intensive Care Med 2007;33:66-73.

41. van Gool WA, van de Beek D, Eikelenboom P. Systemic infection and delirium: When cytokines and acetylcholine collide. Lancet 2010;375:773-5.

42. Cibelli M, Fidalgo AR, Terrando N, et al. Role of interleukin-1beta in postoperative cognitive dysfunction. Ann Neurol 2010;68:360-8.

43. Haussinger D, Kircheis G, Fischer R, Schliess F, vom Dahl S. Hepatic encephalopathy in chronic liver disease: A clinical manifestation of astrocyte swelling and low-grade cerebral edema? J Hepatol 2000;32:1035-8.

44. Catafau AM, Kulisevsky J, Berna L, et al. Relationship between cerebral perfusion in frontal-limbic-basal ganglia circuits and neuropsychologic impairment in patients with subclinical hepatic encephalopathy. J Nucl Med 2000;41:405-10.

45. Inouye SK, Bogardus ST, Jr., Charpentier PA, et al. A multicomponent intervention to prevent delirium in hospitalized older patients. N Engl J Med 1999;340:669-76.

46. Skrobik Y, Ahern S, Leblanc M, Marquis F, Awissi DK, Kavanagh BP. Protocolized intensive care unit management of analgesia, sedation, and delirium improves analgesia and subsyndromal delirium rates. Anesth Analg 2010;111:451-63. 


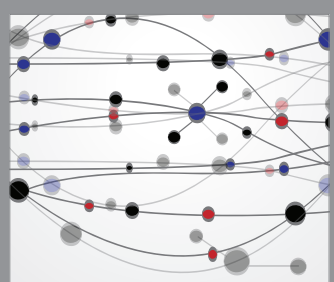

The Scientific World Journal
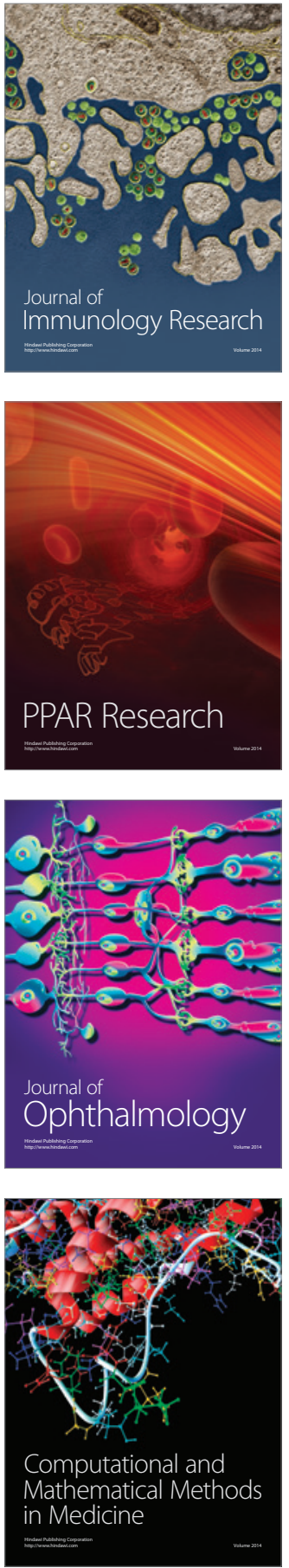

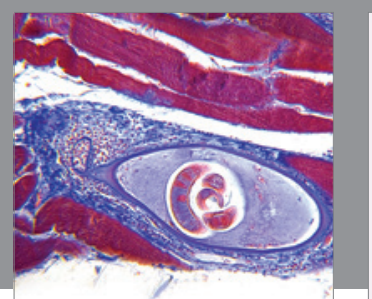

Gastroenterology Research and Practice

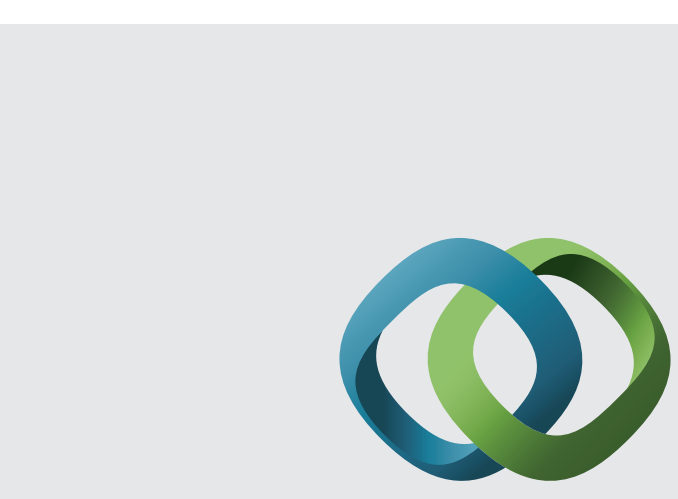

\section{Hindawi}

Submit your manuscripts at

http://www.hindawi.com
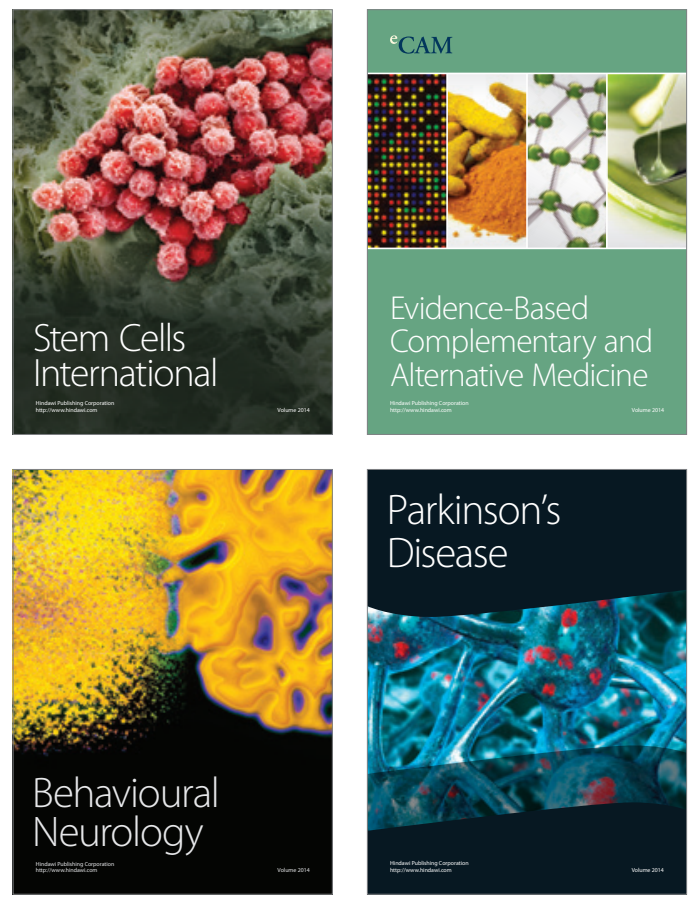
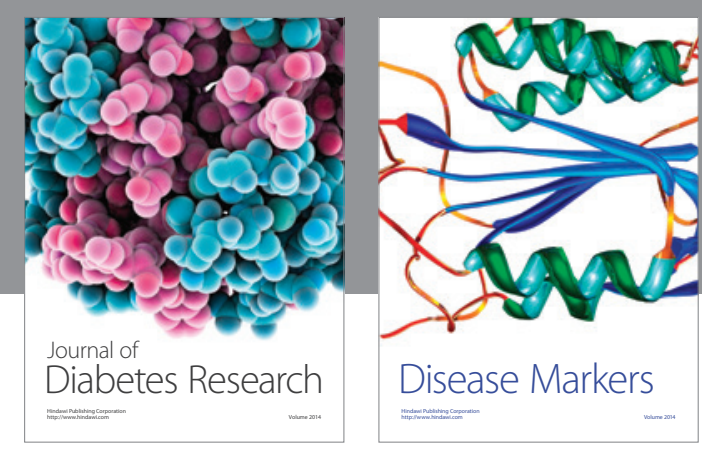

Disease Markers
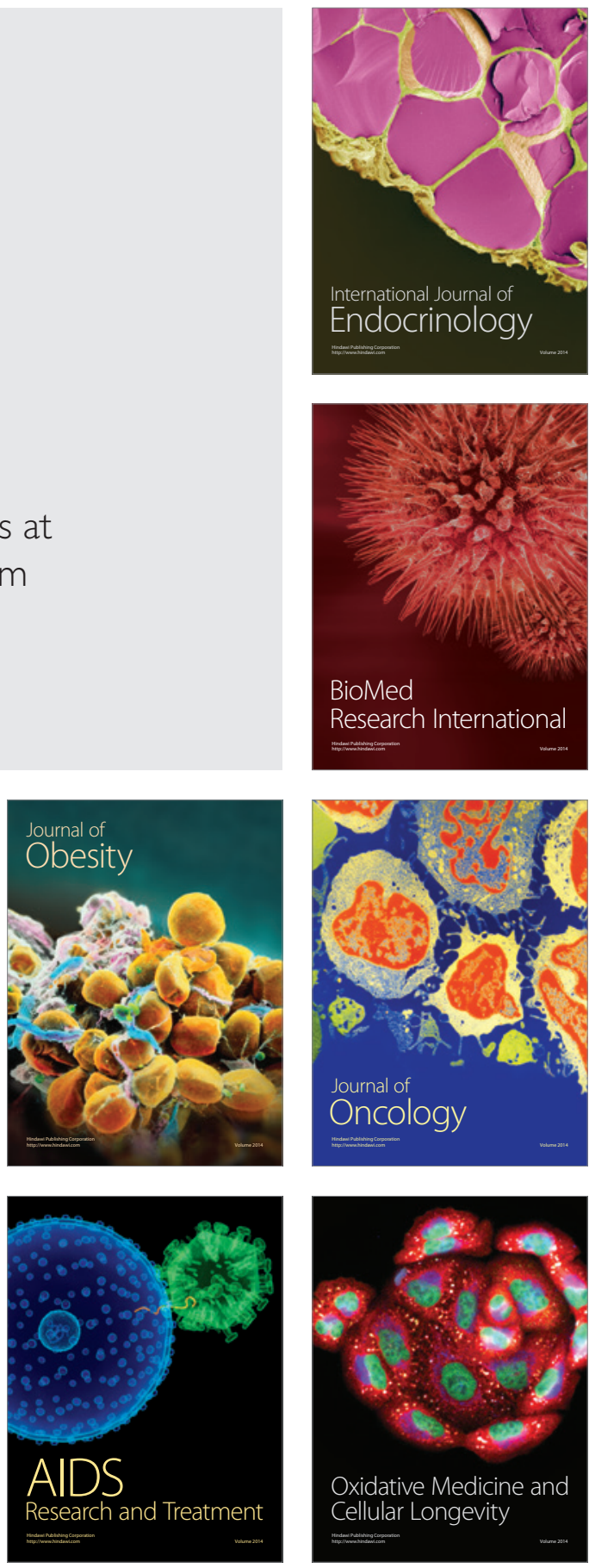